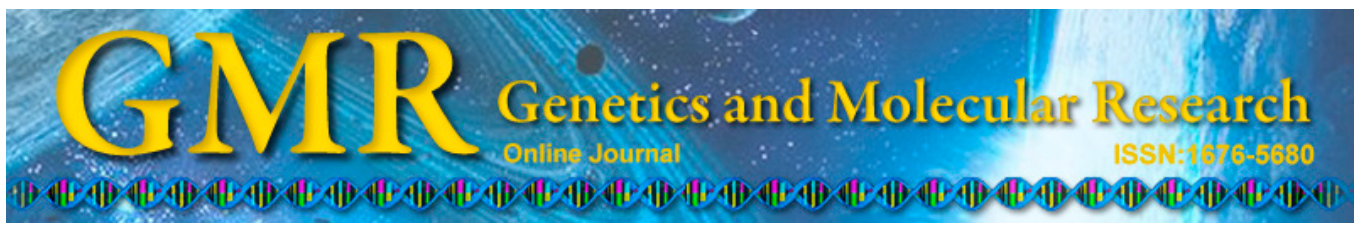

\title{
Quantitative trait locus analysis of grape weight and soluble solid content
}

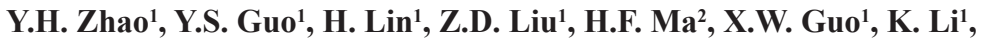 \\ X.X. Yang ${ }^{1}$, Z.Z. Niu ${ }^{1}$ and G.G. Shi ${ }^{1}$
}

${ }^{1}$ College of Horticulture, Shenyang Agricultural University, Shenyang, China ${ }^{2}$ Dalian Academy of Agricultural Science, Dalian, China

Corresponding authors: Y.S. Guo / X.W. Guo

E-mail: guoyinshan77@126.com / guoxw1959@163.com

Genet. Mol. Res. 14 (3): 9872-9881 (2015)

Received December 17, 2014

Accepted May 8, 2015

Published August 19, 2015

DOI http://dx.doi.org/10.4238/2015.August.19.21

\begin{abstract}
A grapevine hybrid population was derived from a crossing of the early-maturing female parent cultivar '87-1' and the late-maturing male parent cultivar '9-22'. A total of 149 plants were selected from the hybrid population as the mapping population, and after sequencerelated amplified polymorphism and simple-sequence repeat marker analysis were conducted we constructed molecular genetic maps of the parents. The molecular linkage map of '87-1' had 19 linkage groups that contained 188 markers, with an average interval of $5.7 \mathrm{cM}$ and a total distance of $1074.5 \mathrm{cM}$; the ' $9-22$ ' map had 19 linkage groups that contained 175 markers, with an average interval of $7.8 \mathrm{cM}$ and a total distance of $1100.2 \mathrm{cM}$. The molecular linkage map of both parents had 19 linkage groups that contained 251 markers, with an average interval of $5.0 \mathrm{cM}$ and a total distance of $1264.2 \mathrm{cM}$. We used the interval mapping method to conduct a quantitative trait locus (QTL) analysis
\end{abstract}


of grape weight and soluble solid content of the mapping population. Six QTLs were related to grape weight, and the average contribution to the phenotypic variance was between 11.3 and $33.0 \%$. Seven QTLs were related to soluble solid content, and the average contribution to the phenotypic variance was between 15.7 and $55.8 \%$.

Key words: Grapevine; Grape weight; Soluble solids; QTL

\section{INTRODUCTION}

Grape (Vitis L.) is one of the most widely cultivated fruits in the world, and in 2012 its global cultivation area was close to 7 million ha and its yield was 67.06 million tons (http:// faostat.fao.org). Grapevines are perennial woody plants that exhibit high genetic heterozygosity, large size, and a long generation cycle. To some extent, the characteristics of grapevines have limited the development of genetic studies on grape traits. Fruit yield and quality are quantitative characteristics. Traditional quantitative genetic research uses mean values and variances to describe the overall genetic characteristics of the quantitative trait in question, and it is difficult to determine the amount of related loci, chromosomal locations, and genetic effects in order to limit the operational capacity of the quantitative trait in breeding programs. Molecular markers are widely used for constructing high-density molecular genetic maps and conducting subsequent the quantitative trait locus (QTL) analysis, in order to determine which loci are related to the trait under investigation.

Ever since Lodhi et al. (1995) constructed the first molecular genetic map of the grapevine, researchers around the world have constructed many high-quality molecular genetic maps using different mapping populations, and conducted QTL analysis for important traits such as fruit aroma (Doligez et al., 2006a; Battilana et al., 2009), Pierce's disease (Krivanek et al., 2006; Riaz et al., 2006, 2008), anti-nematode resistance (Xu et al., 2008), resistance to powdery mildew (Fischer et al., 2004; Akkurt et al., 2007; Zyprian et al., 2009), and antiphylloxera (Zhang et al., 2009).

Developing large grapes with a high sugar content is one of the most important objectives of grapevine breeding. Previous studies have conducted genetic analyses on fruit size and soluble solid content in grapes (Lin et al., 1993; Wang et al., 1997; Luo and He, 1999; Guo et al., 2004), but few studies have reported QTL locations for fruit weight and soluble solid content. However, Doligez et al. (2002), Fanizza et al. (2005), and Mejía et al. (2007) have obtained the QTLs related to fruit weight.

In this study, after crossing an early maturing female parent with a late-maturing male parent, we used sequence-related amplified polymorphism (SRAP) and simple-sequence repeat (SSR) molecular markers to construct molecular genetic maps and conduct QTL analysis for fruit size and soluble solid content. Our results should provide the basis for breeding large and high-quality grapes in the future.

\section{MATERIAL AND METHODS}

\section{Plant materials}

A total of $149 \mathrm{~F}_{1}$ hybrid plants were obtained in 2007 using the cultivar ' $87-1$ ' as the 
female parent and ' $9-22$ ' as the male parent at the Academy of Agricultural Science, Dalian, China.

\section{DNA extraction}

Total genomic DNA was extracted from the leaves using the cetyltrimethylammonium bromide method (Hanania et al., 2004).

\section{SSR primers and polymerase chain reaction (PCR) amplification}

We used 468 pairs of SSR primers, including the VMC series, the VVS series (Thomas and Scott, 1993), the VVMD series (Bowers et al., 1996, 1999), the VrZAG series (Sefc et al., 1999), the VVI series (Merdinoglu et al., 2005), the UDV series (Di Gaspero et al., 2005), the Chr series (Blasi et al., 2011), and the VLG series, which were obtained from genomic sequence information. The PCR volume was $16 \mu \mathrm{L}$, which contained $10 \mathrm{ng}$ DNA, $2.0 \mathrm{mM}$ $\mathrm{Mg}^{2+}, 100 \mu \mathrm{M}$ dNTPs, $0.3 \mu \mathrm{M}$ primer, $0.8 \mathrm{U}$ Taq DNA polymerase, and 1X PCR buffer. The protocol for the PCR amplification was an initial denaturation for 4 min at $94^{\circ} \mathrm{C}$, denaturation for $60 \mathrm{~s}$ at $94^{\circ} \mathrm{C}$, annealing for $60 \mathrm{~s}$ at $50^{\circ}-63^{\circ} \mathrm{C}$, extension for $60 \mathrm{~s}$ at $72^{\circ} \mathrm{C}$ for $25 \mathrm{cycles}$, and an extension for $7 \mathrm{~min}$ at $72^{\circ} \mathrm{C}$. The amplification products were separated by electrophoresis on $5 \%$ polyacrylamide gels and silver stained.

\section{SRAP primers and PCR amplification}

See Li and Quiros (2001) for information regarding the SRAP primers. We used 30 pairs of SRAP primer combinations to construct the maps, which exhibited stable amplification, clear banding patterns, and were rich in polymorphisms. The PCR volume was $20 \mu \mathrm{L}$, which contained $20 \mathrm{ng}$ template DNA, $2.0 \mathrm{mM} \mathrm{Mg}{ }^{2+}, 100 \mu \mathrm{M}$ dNTPs, $0.5 \mu \mathrm{M}$ primer, 1.5 U Taq DNA polymerase, and 1X PCR buffer. The protocol for the PCR amplification was an initial denaturation for $5 \mathrm{~min}$ at $94^{\circ} \mathrm{C}$, denaturation for $60 \mathrm{~s}$ at $94^{\circ} \mathrm{C}$, annealing for $60 \mathrm{~s}$ at $35^{\circ} \mathrm{C}$, extension for $90 \mathrm{~s}$ at $72^{\circ} \mathrm{C}$ for five cycles, denaturation for $60 \mathrm{~s}$ at $94^{\circ} \mathrm{C}$, annealing for $60 \mathrm{~s}$ at $50^{\circ} \mathrm{C}$, extension for $90 \mathrm{~s}$ at $72^{\circ} \mathrm{C}$ for $35 \mathrm{cycles}$, and a final extension for $10 \mathrm{~min}$ at $72^{\circ} \mathrm{C}$. The amplification products were separated by electrophoresis on $7 \%$ polyacrylamide gels and silver stained.

\section{Fruit trait determination}

We measured the weights and soluble solid contents of the grapes of every individual plant once they were mature. For grape weight, we averaged the weights of 30 randomly selected grapes, and soluble solid content was measured using a hand-held sugar-measuring instrument; we took the average soluble solid content of 10 random fruits.

\section{Construction of genetic maps and QTL analysis}

We used JoinMap 3.0 to construct molecular genetic maps with the CP mapping 
model, a $\log$ of the odds value of 4.0, and a maximum recombination value of 0.4 . We converted the recombination value into map distance (cM) using the Kosambi function, and constructed linkage maps of the two parents using MapChart 2.2. The linkage groups were ordered according to the international reference map coding (Doligez et al., 2006b). We used MapQTL 5.0 to conduct interval mapping, in order to determine the QTL threshold.

\section{RESULTS}

\section{Molecular marker analysis and genetic map construction}

From the 468 pairs of SSR primers we screened out 200 pairs to construct the genetic maps, and obtained 44 special female markers and 54 special male markers and 102 markers that were shared by the two parents. From the 30 pairs of SRAP primers we obtained 53 special female markers and 27 special male markers, and 39 markers that were shared by the two parents.

Using the 97 special female markers and the 141 markers that were shared by the two parents we constructed a genetic map of female parent ' $87-1$ '; 188 markers were added to the genetic map, which had a total length of $1074.5 \mathrm{cM}$ (Figure 1). These markers constituted 19 linkage groups; the average length of the groups was $56.6 \mathrm{cM}$, and the average distance between each marker was $5.7 \mathrm{cM}$. The longest group (LG19) contained nine SSR markers and five SRAP markers, and the length of the linkage group was $111 \mathrm{cM}$.

Using the 81 special male markers and the 141 markers that were shared by the two parents we constructed a genetic map of male parent ' $9-22$ '; 175 markers were added to the genetic map, which had a total length of $1100.2 \mathrm{cM}$ (Figure 1). These markers constituted 19 linkage groups; the average length of the groups was $57.9 \mathrm{cM}$, and the average distance between each marker was $7.8 \mathrm{cM}$. The longest group (LG12) contained nine SSR markers and five SRAP markers, and the length of the linkage group was $107.4 \mathrm{cM}$.

Using all of the 319 markers to construct a genetic map that was shared by the two parents, 251 markers were added to the genetic map, which had a total length of $1264.2 \mathrm{cM}$. These markers constituted 19 linkage groups; the average length of the groups was 66.5 $\mathrm{cM}$, and the average distance between each marker was $5.0 \mathrm{cM}$ (Figure 1).

\section{Fruit trait measurements and QTL locations}

Figure 2 shows frequency distributions for fruit weight and soluble solid content of the mapping population. The grape weights of the filial generation ranged between 1.6 and $10.8 \mathrm{~g}$, and the average was $6.0 \mathrm{~g}$. The soluble solid content ranged between 11.7 and $19.5 \%$, and the average was $15.1 \%$ (Figure 2).

QTLs related to fruit weight were detected in linkage groups 5 and 6 , and the contribution of each QTL to the total phenotypic variation was between 11.3 and $33.0 \%$. QTLs related to soluble solid content were detected in linkage groups 3 and 10-1, and the contribution of each QTL to the total phenotypic variation was between 15.7 and $55.8 \%$ (Table 1). 
Y.H. Zhao et al.

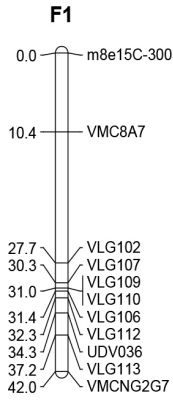

\section{C1}

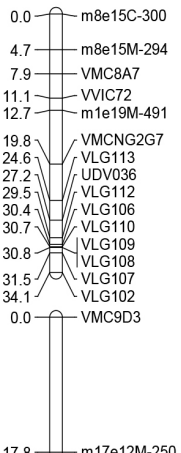

F2

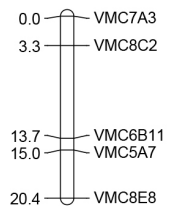

F4

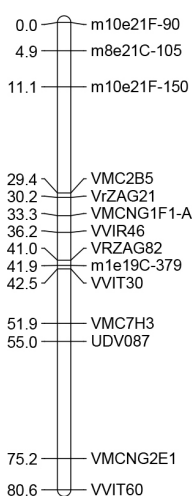

80.6-VVIT60

F7

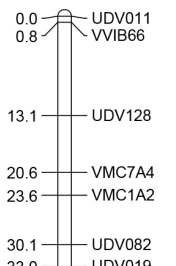

33.0_— UDV019

C4

C7
M1

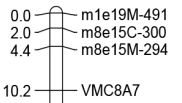

10.2 - VMC8A7
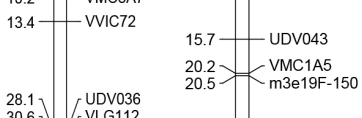

$\left.\begin{array}{l}28.1 \\ 30.6\end{array}\right] \quad$ UDV036

1.9 VLG108

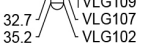

$0.0-\mathrm{VMC} 9 \mathrm{D} 3$

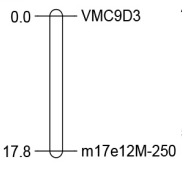

M2
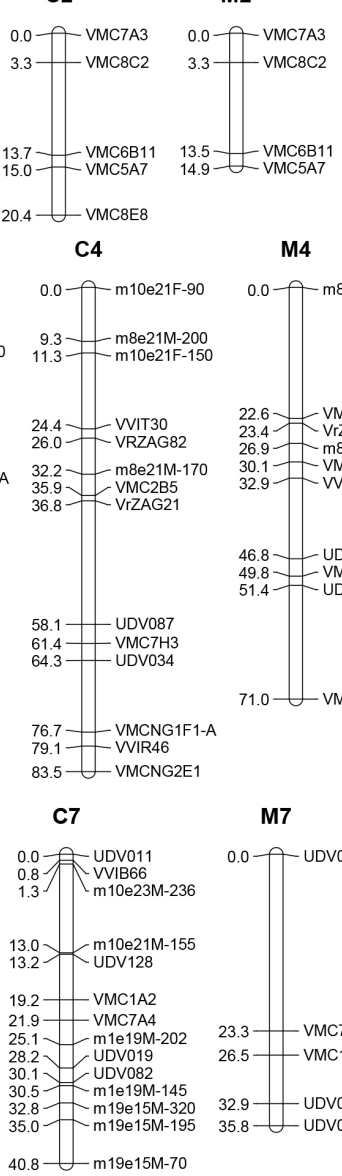

F3

F5
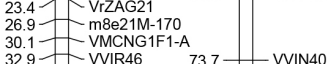

F6

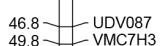

49.8 - VMC7H3

- VDVO34

$71.0-$ VMCNG2E1

\section{M7}

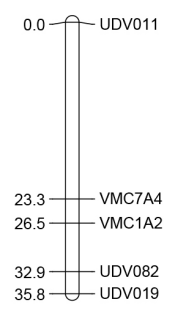

$31.5 \sqrt{\text { VLG106 }}$
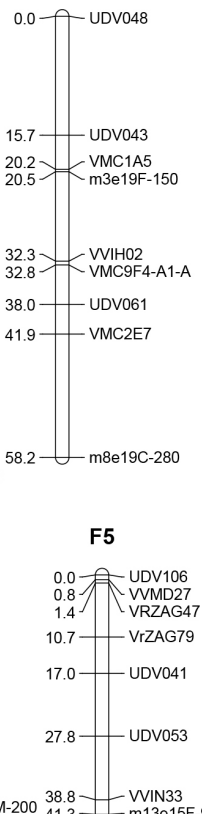

38.8- VVIN33

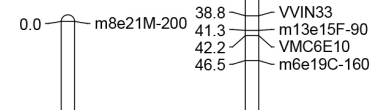

46.5 m6e19C-160

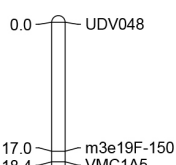

$\begin{array}{ll}17.0 & \text { m3e19F-150 } \\ 18.4 & \text { VMC1A5 }\end{array}$

24.8- UDV043

35.3 V VMC2E7

$36.2]$ VVIHO2

6.1
$6.13 \mathrm{e} 15 \mathrm{C}-120$
$\mathrm{~m} 3 \mathrm{e} 19 \mathrm{M}-155$

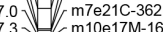

m7e21F-400
m7e21C-201

51.5 m7e21F-271

61.4- m8e19C-280

64.2- $\mathrm{m} 8 \mathrm{e} 219 \mathrm{C}-280$

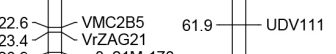

26.9 - m8221M-170

$73.7-$ VVIN40
$78.0-$ VMC4C6

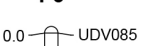

0.0- UDV085

$8.0{ }_{\mathrm{m}}^{\mathrm{me} 19 \mathrm{~F}-290}$

9.07 VMC2G

$\begin{array}{lll}\text { VMC2H9 } & \text { VM.2 } \\ \text { m6e2OF-280 } & \end{array}$

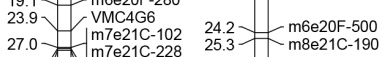

27.2 $\begin{aligned} & \mathrm{m} 7 \mathrm{e} 21 \mathrm{C}-228 \\ & \mathrm{mBe} 15 \mathrm{C}-392\end{aligned}$

34.4 $\prod_{\text {m6e20F-500 }}^{27.5}$
C3

$=\left(\begin{array}{lll}\text { VMC9F4-A1-A } & 32.7-\text { m6e20C-100 } \\ \text { UDV061 }\end{array}\right.$

C5

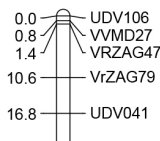

32.7.4 VVIN33

36.0 VMC6E10 36.2 - m20e15M-163
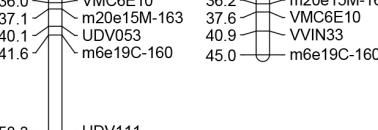

M3

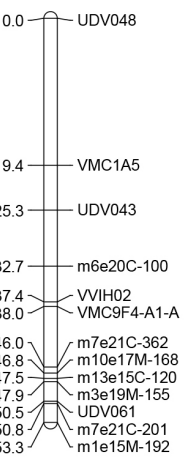

M5

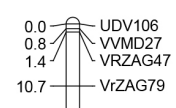

17.7 VIZAG79

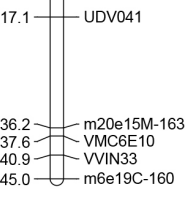

$58.3-$ UDV111

$70.2-$ VVIN40
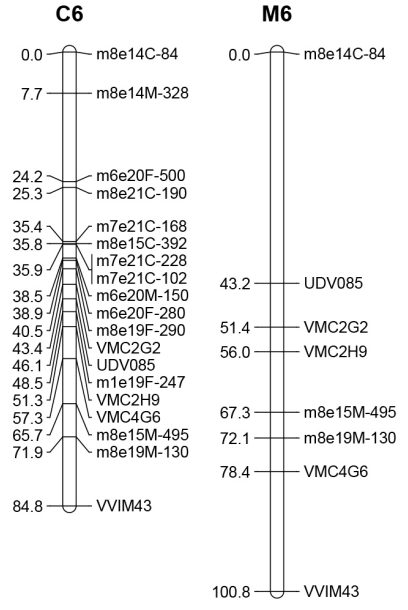

Figure 1. Linkage map of Vitis vinifera 87-1 x 9-22. Linkage groups are numbered according to Doligez et al. (2006b). For each linkage group, the parental maps are shown on the left (87-1) and right (9-22) and the consensus map is in the center. Distances of markers from the top are indicated on the left in cM Kosambi.

Continued on next page 
Figure 1. Continued.

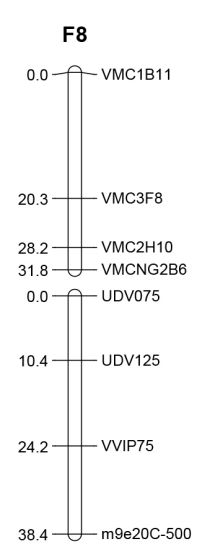

F10

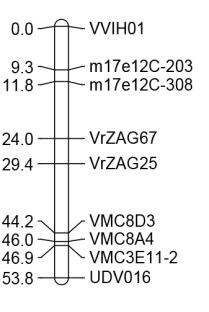

$0.0-\mathrm{m} 7 \mathrm{e} 12 \mathrm{~F}-181$

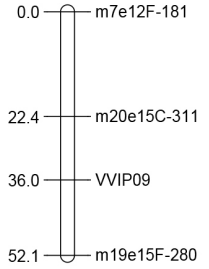

C8

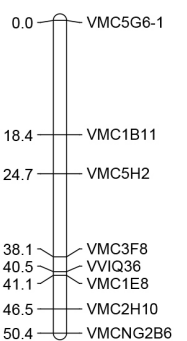

$50.4 U_{\text {VMCNG2B6 }} \quad 50.1 \bigcup_{\text {VMCNG2B } 6}$

$0.0-$ UDV075

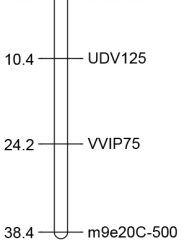

C10
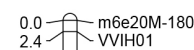

$11.5-\mathrm{m} 17 \mathrm{e} 12 \mathrm{C}-203$
$\mathrm{~m} 17 \mathrm{e} 12 \mathrm{C}-308$

20.0- UDV073

26.8 VrZAG67

\begin{tabular}{ll|l}
27.9 & VVIR21 \\
32.7 & VrZAG25
\end{tabular}

45.9 VMC2A9-DG

6.1 VMC8D3

48.0 - VMC8A4

V.9. VMC3E11-2
UDV016

0.0 - $\mathrm{m} 7 \mathrm{e} 12 \mathrm{~F}-181$

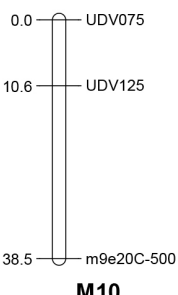

M10

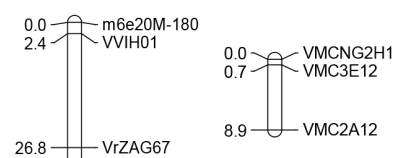

-m17e12C-308 ${ }^{0.0}$ - $\mathrm{m} 7 \mathrm{e} 14 \mathrm{~F}-318$

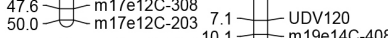

. m19e14C-408

\begin{tabular}{l|l}
0.0 & $\mathrm{~m} 20 \mathrm{e} 15 \mathrm{C}-311$ \\
\hline & UDV073
\end{tabular}

\begin{tabular}{l|l}
13.7 & VVIR21
\end{tabular}

\begin{tabular}{l|l}
16.5 & - VMCNG2H7-DG-C
\end{tabular}

$\begin{array}{ll}24.6 & \text { m } 10 \mathrm{e} 23 \mathrm{~F}-155 \\ 27.8 & \text { VMMCNG2H7-DG-B }\end{array}$

37.6

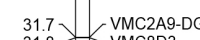

3.. 2 VMC8D3

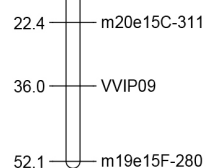

F12
C9

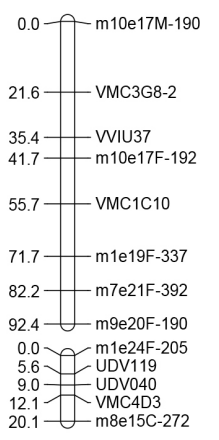

C11

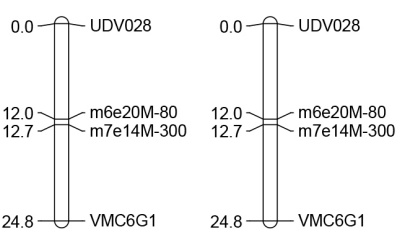

0.0 VMCNE12

$8.9-$ VMC2A12

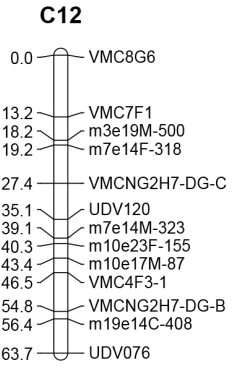
$0.0-$ m7e21M-75
$3.2-$ UDV024
$6.4-$ VMC1G3-2

\section{M9}

0.0 f $^{\mathrm{m} 10 \mathrm{e} 17 \mathrm{M}-190}$

21.9- VMC3G8-2

\begin{tabular}{l|l}
$35.4-$ VIU37 \\
\hline
\end{tabular}

$53.2-\mathrm{VMC} 1 \mathrm{C} 10$

0.0 VMC5C1

$2.4{ }_{\mathrm{m} 8 \mathrm{e} 15 \mathrm{C}-272}$

8.7 VMC3H5

18.8 ${ }_{\mathrm{m} 13 \mathrm{e} 15 \mathrm{M}-650}$

11

M11
48.8-UDV076 
Figure 1. Continued.

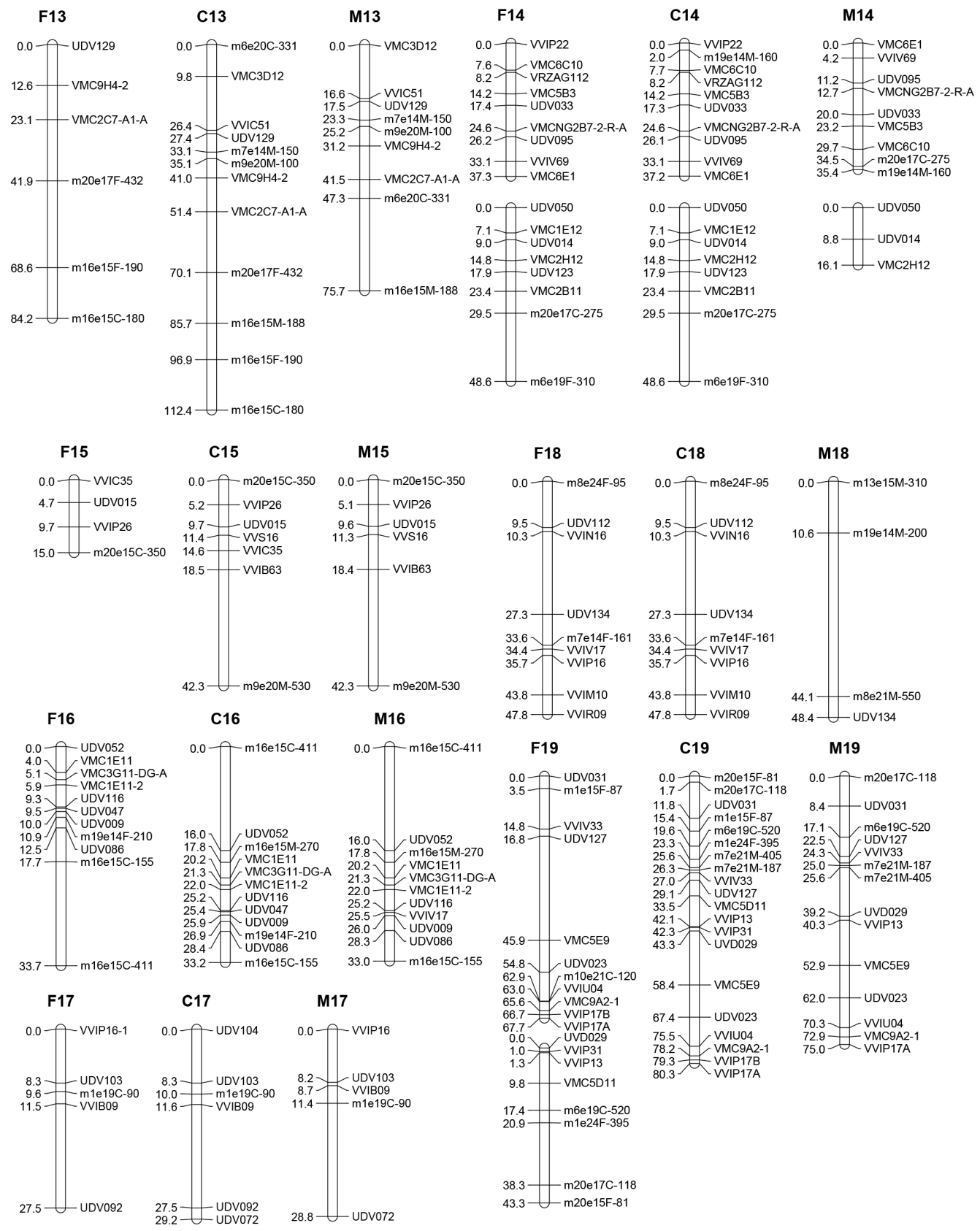



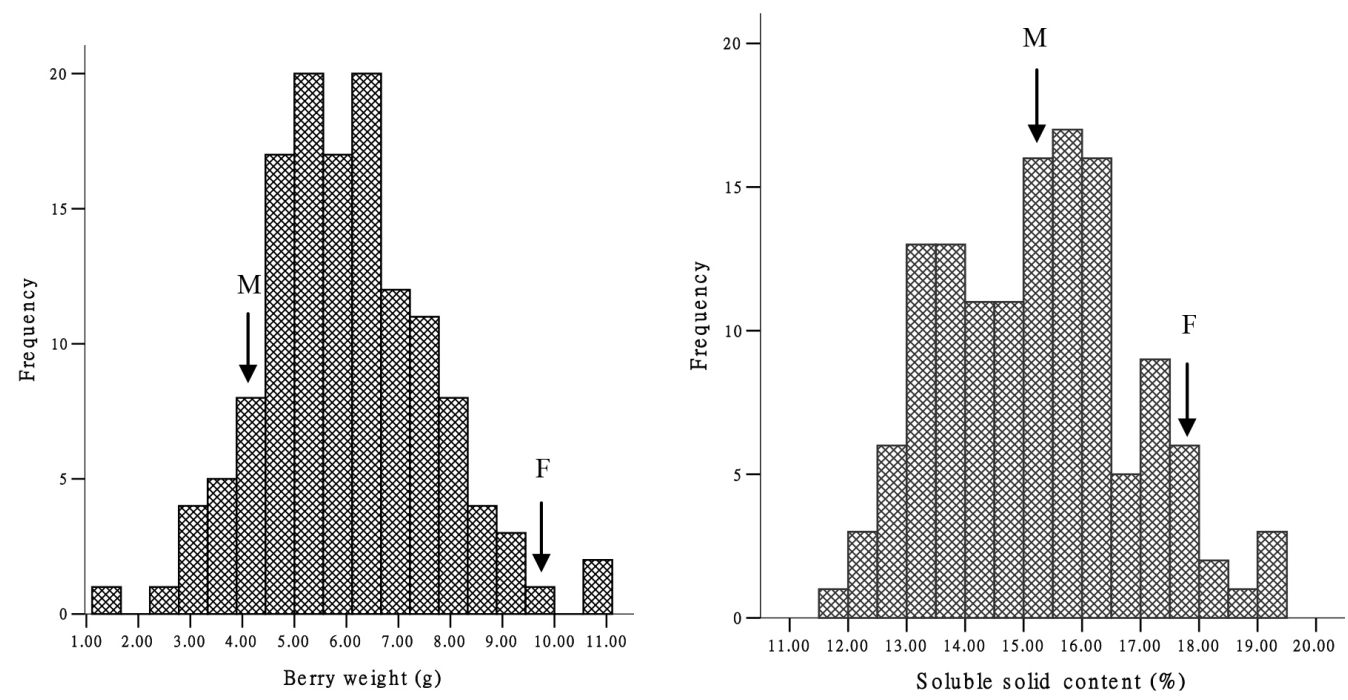

Figure 2. Frequency distribution of the 149 progeny plants for each trait. Parental phenotypes are indicated by arrows. $\mathrm{M}=87-1, \mathrm{~F}=9-22$.

Table 1. Quantitative trait locus distribution for grape weight and soluble solid content in the genetic linkage map.

\begin{tabular}{|c|c|c|c|c|c|c|c|}
\hline Trait & Linkage group $^{a}$ & $\mathrm{Map}^{\mathrm{b}}$ & LOD score & LOD threshold ${ }^{c}$ & Nearest marker & Peak (cM) & $R^{2}(\%)$ \\
\hline \multirow[t]{6}{*}{ Grape weight } & 5 & M & 2.86 & 2.70 & VVMD27 & 0.83 & 12.5 \\
\hline & 5 & $\mathrm{~F}$ & 3.62 & 2.80 & VVMD27 & 0.83 & 12.5 \\
\hline & 5 & $\mathrm{C}$ & 3.63 & 3.00 & VVMD27 & 73.8 & 12.5 \\
\hline & 6 & $\mathrm{~F}$ & 2.95 & 2.90 & M6e20F-500 & 34.4 & 11.3 \\
\hline & 6 & $\mathrm{C}$ & 3.58 & 3.10 & M8e14C-84, m8e14M-328 & 5.0 & 33.0 \\
\hline & 6 & $\mathrm{C}$ & 3.11 & 3.10 & M6e20F-500 & 24.2 & 12.4 \\
\hline \multirow[t]{7}{*}{ Soluble solid content } & 3 & M & 4.21 & 3.20 & m6e20C-100, VVIH02 & 36.6 & 16.6 \\
\hline & 3 & M & 5.34 & 3.20 & VMC9F4-A1-A, m7e21C-362 & 41.0 & 55.8 \\
\hline & 3 & M & 3.44 & 3.20 & m3e19M-155, UDV061 & 48.9 & 28.9 \\
\hline & 3 & $\mathrm{~F}$ & 4.44 & 2.90 & m3e19F-150, VVIH02 & 29.5 & 33.2 \\
\hline & 3 & $\mathrm{C}$ & 4.30 & 3.10 & m6e20C-100, VVIH02 & 35.7 & 16.6 \\
\hline & 3 & $\mathrm{C}$ & 3.12 & 3.10 & m1e15M-192, m8e19C-280 & 54.5 & 15.7 \\
\hline & $10-1$ & $\mathrm{~F}$ & 2.33 & 2.30 & M7e12F-181, M20E15C-311 & 8.0 & 40.5 \\
\hline
\end{tabular}

a Linkage group according to the International Grape Genome Program (IGGP). ' $\mathrm{M}=$ '87-1'; F = '9-22'; C = consensus. ${ }^{c}$ Determined by a permutation test at $\mathrm{P} \leq 0.05 . \mathrm{LOD}=\log$ of the odds.

\section{DISCUSSION}

Our results show that fruit weight and soluble solid content are quantitative traits that were widely segregated in the filial generation. Mejía et al. (2007) found QTLs related to fruit weight in linkage groups 15 and 18, and Doligez et al. (2002) found QTLs in linkage groups 12 and x. However, Fanizza et al. (2005) found QTLs in linkage groups 4, 5, 13, 16, and 20 over 3 years.

In this study, we detected QTLs related to fruit weight in the female parent map, the male parent map, and in linkage group 5 that was shared by the two parents, and the loci were co-segregated with the molecular marker VVMD27. We detected QTLs related to soluble solid content in linkage group 3, and the molecular marker was VVIH02. In the future, we will 
increase the density of the genetic map and improve its accuracy, and we will also conduct QTL analysis in different years. This approach will allow us to test the stability of the QTLs over time, and lay the foundations for refined QTL detection and marker-assisted selection.

\section{Conflicts of interest}

The authors declare no conflict of interest.

\section{ACKNOWLEDGMENTS}

Research supported by the National Natural Science Funds of China (grants \#31372021 and \#31000894), the China Agriculture Research System (grant \#CRAS-30yz-6), the Specialized Research Fund for the Doctoral Program of Higher Education (grant \#20102103120003), the Research Project in Liaoning Province Science and Technology Department (grant \#2014204004), the Foundation of Liaoning Educational Committee (grant \#L2010492), the Youth Foundation of Shenyang Agricultural University (grant \#20092005), and the Shenyang Science and Technology Development Fund (grant \#201207).

\section{REFERENCES}

Akkurt M, Welter L, Maul E, Reinhard T, et al. (2007). Development of SCAR markers linked to powdery mildew (Uncinula necator) resistance in grapevine (Vitis vinifera L. and Vitis sp.). Mol. Breed. 19: 103-111.

Battilana J, Costantini, Emanuelli F, Sevini F, et al. (2009). The 1-deoxy-D-xylulose 5-phosphate synthase gene colocalizes with a major QTL affecting monoterpene content in grapevine. Theor. Appl. Genet. 118: 653-669.

Blasi P, Blanc S, Wiedemann-Merdinoglu S, Prado E, et al. (2011). Construction of a reference linkage map of Vitis amurensis and genetic mapping of Rpv8, a locus conferring resistance to grapevine downy mildew. Theor. Appl. Genet. 123: 43-53.

Bowers JE, Dangl GS, Vignani R and Meredith C (1996). Isolation and characterization of new polymorphic simple sequence repeat loci in grape (Vitis vinifera L.). Genome 39: 628-633.

Bowers JE, Dangl GS and Meredith C (1999). Development and characterization of additional microsatellite DNA markers for grape. Am. J. Enol. Vitic. 50: 243-246.

Di Gaspero G, Cipriani G, Marrazzo MT, Andretta D, et al. (2005). Isolation of (AC)n-microsatellites in Vitis vinifera L. and analysis of genetic background in grapevines under marker assisted selection. Mol. Breed. 15: 11-20.

Doligez A, Bouquet A, Danglot Y, Lahogue F, et al. (2002). Genetic mapping of grapevine (Vitis vinifera L.) applied to the detection of QTLs for seedlessness and berry weight. Theor. Appl. Genet. 105: 780-795.

Doligez A, Audiot E, Baumes R and This P (2006a). QTLs for muscat flavor and monoterpenic odorant content in grapevine (Vitis vinifera L.). Mol. Breed. 18: 109-125.

Doligez A, Adam-Blondon A-F, Cipriani G, Di Gaspero G, et al. (2006b). An integrated SSR map of grapevine based on five mapping populations. Theor. Appl. Genet. 113: 369-382.

Fanizza G, Lamaj F, Costantini L, Chaabane R, et al. (2005). QTL analysis for fruit yield components in table grapes (Vitis vinifera). Theor. Appl. Genet. 111: 658-664.

Fischer BM, Salakhutdinov I, Akkurt M, Eibach R, et al. (2004). Quantitative trait locus analysis of fungal disease resistance factors on a molecular map of grapevine. Theor. Appl. Genet. 108: 501-515.

Guo XW, Guo YS, Li YH, Li CX, et al. (2004). Studies on the inheritance trend of the main economic characteristics of crossed grape progeny. J. Fruit Sci. 21: 319-323.

Hanania U, Velcheva M, Sahar N and Perl A (2004). An improved method for isolating high-quality DNA from Vitis vinifera nuclei. Plant Mol. Biol. Rep. 22: 173-177.

Krivanek A, Riaz FS and Walker MA (2006). Identification and molecular mapping of PdR1, a primary resistance gene to Pierce's disease in Vitis. Theor. Appl. Genet. 112: 1125-1131.

Li G and Quiros CF (2001). Sequence-related amplified polymorphism (SRAP), a new marker system based on a simple PCR reaction: Its application to mapping and gene tagging in Brassica. Theor. Appl. Genet. 103: 455-461. 
Lin, XG, Yin LR, Shen YJ, Sun KJ, et al. (1993). Character inheritance of offspring in the intraspecific hybridization of Vitis amurensis Rupr. Acta Hort. Sin. 20: 231-236.

Lodhi MA, Daly MJ, Ye GN, Weeden NF, et al. (1995). A molecular marker based linkage map of Vitis. Genome 38: 786-794.

Luo SL and He PC (1999). Inheritance of cluster and berry traits of F1 interspecific hybrids among Vitis species. SinoOverseas Grapevine Wine 4: 17-21.

Mejía N, Gebauer M, Muñoz L, Hewstone N, et al. (2007). Identification of QTLs for seedlessness, berry size, and ripening date in a seedless x seedless table grape progeny. Am. J. Enol. Vitic. 58: 499-507.

Merdinoglu D, Butterlin G, Bevilacqua L, Chiquet V, et al. (2005). Development and characterization of a large set of microsatellite markers in grapevine (Vitis vinifera L.) suitable for multiplex PCR. Mol. Breed. 15: 349-366.

Riaz S, Krivanek AF, Xu K and Walker MA (2006). Refined mapping of the Pierce's disease resistance locus, PdR1, and Sex on an extended genetic map of Vitis rupestris x V. arizonica. Theor. Appl. Genet. 113: 1317-1329.

Riaz S, Tenscher AC, Rubin J, Graziani R, et al. (2008). Fine-scale genetic mapping of two Pierce's disease resistance loci and a major segregation distortion region on chromosome 14 of grape. Theor. Appl. Genet. 117: 671-681.

Sefc KM, Regner F, Turetschek E, Glössl J, et al. (1999). Identification of microsatellite sequences in Vitis riparia and their applicability for genotyping of different Vitis species. Genome 42: 367-373.

Thomas MR and Scott N (1993). Microsatellite repeats in grapevine reveal DNA polymorphisms when analyzed as sequence-tagged sites (STSs). Theor. Appl. Genet. 6: 985-990.

Wang J, Song RG, Yin LR and Sun KJ (1997). Genetic characteristics of hybrids from the cross between $V$. amurensis and V. vinifera. Special Wild Econ. Anim. Plant Res. 1: 5-9.

Xu K, Riaz S, Roncoroni NC, Jin Y, et al. (2008). Genetic and QTL analysis of resistance to Xiphinema index in a grapevine cross. Theor. Appl. Genet. 116: 305-311.

Zhang JK, Hausmann L, Eibach R, Welter LJ, et al. (2009). A framework map from grapevine V3125 (Vitis vinifera 'Schiava grossa' x 'Riesling') x rootstock cultivar 'Börner' (Vitis riparia x Vitis cinerea) to localize genetic determinants of phylloxera root resistance. Theor. Appl. Genet. 119: 1039-1051.

Zyprian E, Welter LJ, Akkurt M, Ebert S, et al. (2009). Genetic analysis of fungal disease resistance in grapevine. Acta Hort. 827: 535-538. 